\title{
Avestruces en Hispania: cuestiones en torno al resto hallado en Cartagena (s. v-VI d. C.)
}

\author{
Ostriches in Hispania: issues raised by a find from Cartagena \\ (5th-6th c. AD).
}

\section{JuAN E. PADILla-SÁNCHEZ}

Universidad de Murcia. Departamento de Prehistoria, Arqueología, Historia Antigua, Historia Medieval y Ciencias y Técnicas Historiográficas. Facultad de Letras

C/ Santo Cristo, 1, E-30001 Murcia

juanenrique.padilla@um.es

\section{Sebastián F. Ramallo Asensio}

Universidad de Murcia. Departamento de Prehistoria, Arqueología, Historia Antigua, Historia Medieval y Ciencias y Técnicas Historiográficas. Facultad de Letras C/ Santo Cristo, 1, E-30001 Murcia sfra@um.es

\section{Arturo Morales MuÑIZ}

Universidad Autónoma de Madrid. Laboratorio de Arqueozoología. Departamento de Biología C/ Darwin, 2, E-28049 Madrid

arturo.morales@uam.es

Es detalla la troballa d'un tars-metatars d'estruç, recuperat en un abocador ubicat sobre el mercat/ magatzem que des de mitjan segle v d. C. a principis del vi d. C. es va situar sobre el teatre romà de Cartagena. La presència de l'au, associada a estructures tardanes superposades a l'edifici d'espectacles en aquesta zona portuària, fa llum sobre el comerç, la societat i la cultura del moment. En clar contrast amb l'abundància d'evidències a les fonts clàssiques i iconogràfiques, només tres restes d'estruços s'han pogut testificar fins ara en registres arqueològics de l'àmbit mediterrani. 
This paper provides details of the find of an ostrich tarso-metatarsal recovered in rubbish dumped in the market/warehouse that from the mid- 5th century $\mathrm{AD}$ to the beginning of the 6th century $\mathrm{AD}$ was built over the Roman Theatre of Cartagena. The association of the find with late Antique structures overlying a building for entertainment in such a significant port offers important insights on the trade, society and culture of the time. In contrast with the abundant data reported by the classical and iconographic sources, only three ostrich remains have been thus far reported from the Mediterranean archaeological record.

\section{KEY-WORDS}

OSTRICH, LATE-ANTIQUITY, EXOTIC FAUNA, TRADE, COMMENSALITY, CARTAGENA

Se detalla el hallazgo de un tarso-metatarso de avestruz, recuperado en un basurero ubicado sobre el mercado/almacén que desde mediados del siglo $\mathrm{v}$ d. C. a principios del vi d. C. se situó sobre el teatro romano de Cartagena. La presencia del ave, asociada a estructuras tardías superpuestas al edificio de espectáculos en esta zona portuaria, arroja luz sobre el comercio, la sociedad y la cultura del momento. En claro contraste con la abundancia de evidencias en las fuentes clásicas e iconográficas, solo tres restos de avestruces han podido atestiguarse hasta la fecha en registros arqueológicos del ámbito mediterráneo.

\section{PALABRAS CLAVE}

AVESTRUZ, ANTIGÜEDAD TARDÍA, FAUNA EXÓTICA, COMERCIO, COMENSALIDAD, CARTAGENA

\section{Introducción}

El nombre científico del avestruz (Struthio camelus L., 1758) procede de la definición que Opiano de Apamea ofrece en su tratado De la caza y de la pesca (Calvo, 1990: 480 y ss.), donde describe el ave como un "camello unido a un pardal» (vid. también Diodoro Sículo, II, 50, 3 ). En la actualidad, la distribución geográfica de la especie se limita a bosques, sabanas y pastizales del África subsahariana, pero fue mucho más amplia en el pasado (Cramp, 1975). Esta repartición alcanzó el norte de África, la península de Arabia y el centro del Asia más occidental, habiendo constancia escrita de introducción antrópica en distintos puntos del Mediterráneo septentrional en época romana (Reese, 1985: 371-382; Camps-Fabrer, 1995; Brysbaert, 2013). Herodiano (I, 15, 5) se refiere a los «avestruces de Mauritania» al describir los espectáculos públicos ofrecidos por Cómodo en el anfiteatro, en los que el emperador los decapitaba con flechas con la punta en forma de media luna para verlos correr descabezados (Torres, 1990: 128).

Como fuente de alimento resulta notable, pues supera a veces los $160 \mathrm{~kg}$, oscilando sus huevos entre 1 y 1,5 kg. Su "potencial lúdico" en tiempos pasados radicaba en la conducta territorial y la consecuente agresividad que esta implica en el macho, lo que lo hacía adecuado para espectáculos venatorios. Estas características, así como su elevada talla (dos metros), explican por qué su distribución se extendió tempranamente más allá de sus territorios de origen, así como su uso en las carreras de bigas y los juegos del anfiteatro, bien representados ambos en el arte romano. Muy apreciados fueron los huevos decorados, utilizados como 
contenedores de agua, tanto vasos como cantimploras (Toynbee, 1973: 237). Estos usos explicarían la comercialización de huevos de avestruz en la península ibérica por parte de los fenicios desde inicios del I milenio a. C., aunque las primeras evidencias se remonten, cuando menos, al III milenio a. C. (Pellicer, 1995: 81-134; Pajuelo, 2016: 455-467; Martín, 2018). Sabemos que la piel fue utilizada para forrar escudos (Heródoto, IV, 175) y la grasa con fines medicinales (Plinio, NH, XXIX, 96), entre otros (vid., en general, Richter, 1975).

Aunque la circulación y comercialización del avestruz es bien conocida a través de la iconografía y las fuentes escritas, no sucede lo mismo con el registro arqueológico, donde su presencia es casi inexistente. Es en el marco de este contexto de excepcionalidad donde cobra relevancia el hallazgo del teatro romano de Cartagena que aquí detallamos. Su aparición en un contexto bien definido añade interés al resto, por cuanto permite realizar inferencias tanto económicas como sociales y culturales, que nos ayudan a completar la visión de Carthago Spartaria.

\section{El avestruz en las fuentes literarias e iconográficas}

Las primeras referencias al avestruz en los textos griegos se remontan al siglo $\mathrm{v}$ a. C. (Jenofonte, Anábasis, I, 5, 3), si bien existen representaciones iconográficas más antiguas, especialmente en Egipto, desde época predinástica (Crompton, 1918). En las fuentes romanas se hace referencia a la historia natural del avestruz, como vemos en Plinio ( $\mathrm{NH}$, X, I; Cantó, 2002), Claudio Eliano (Historia de los animales, II, 27; Vara, 1989) y Opiano de Apamea (De la caza y de la pesca, III, 480 y ss.; Calvo, 1990).

En los tratados de cocina romanos las referencias al avestruz se centran en su carne y el carácter exótico, que lo circunscriben a los paladares de las clases altas de la sociedad. En el tratado de Marco Gavio Apicio, De re coquinaria (VI, I, 1-2; Pastor, 1987: 49), del siglo I d. C., se menciona un plato de ragú de avestruz y se alude a otras recetas en las que el ave es la protagonista. En este entorno cultural gastronómico, su circunscripción a determinados ámbitos sociales queda reflejada en un banquete del emperador Heliogábalo (218-222 d. C.), en el que «hizo servir en múltiples mesas en una sola comida las cabezas de seiscientos avestruces, para que se comieran los sesos» (SHA, Heliogab, 30, 3; Picón y Cascón, 1989: 366).

La segunda fuente de datos sobre el avestruz son los juegos de anfiteatro (Vuković, 2015: 150). Así, por ejemplo, sabemos que Cómodo, a finales del siglo II d. C., decapitaba avestruces en el Coliseo (Gibbon, 1910: 96). La Historia Augusta (Probo, 19, 4; Picón y Cascón, 1989: 691) narra, quizás de manera un tanto exagerada, los juegos que preparó el emperador Probo, donde al parecer se usaron mil avestruces para gozo y disfrute de la plebe. Por último, se tienen referencias de que, en el 202 d. C., Septimio Severo organizó unos juegos donde se masacraron 700 fieras, entre las que se incluían avestruces, sin especificar su número (Blázquez, 1974: 91-97).

Son varios los testimonios en los que aparece representado el avestruz, algunos de ellos corroborando las actividades de los juegos circenses (Toynbee, 1973). Escenas de los 


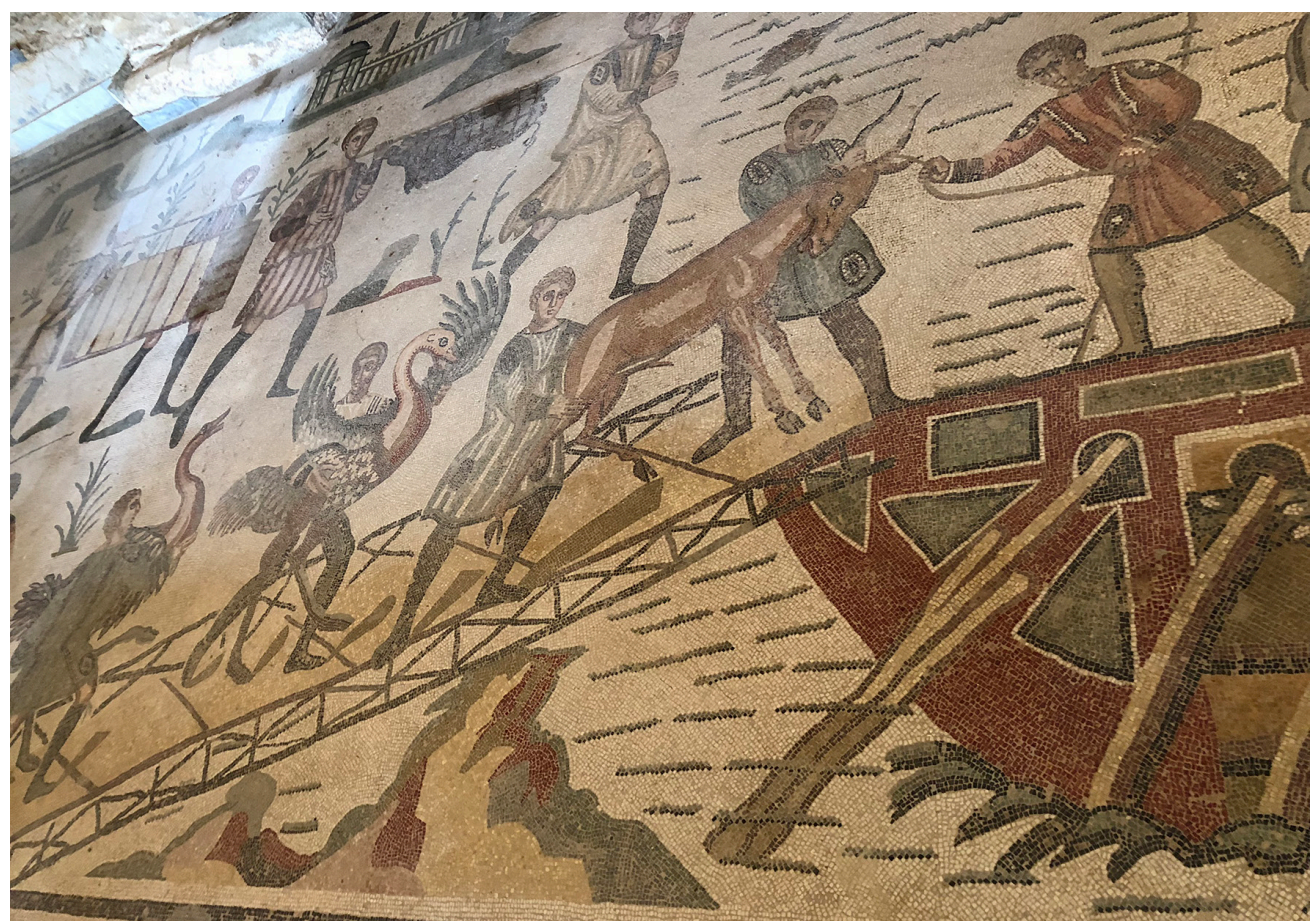

Figura 1. Mosaico de la villa romana del Casale, Piazza Armerina (Sicilia), s. Iv d. C. Fuente: Codex.

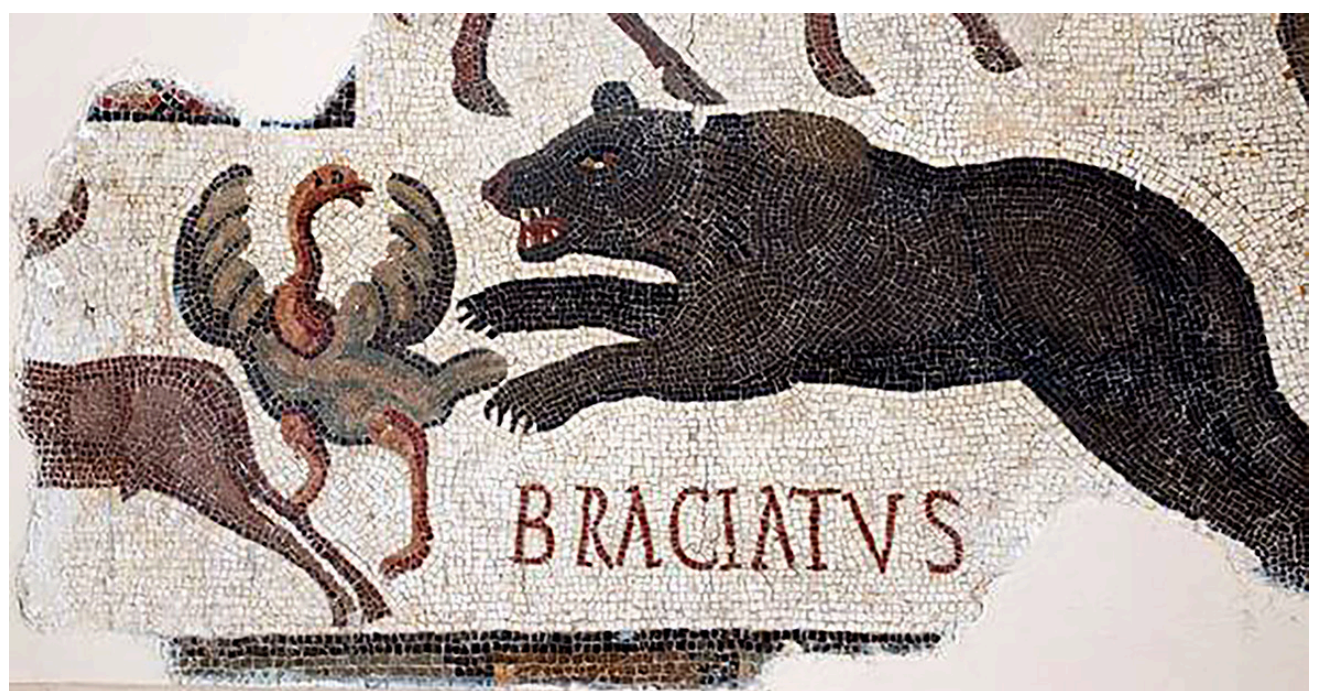

Figura 2. Mosaico romano del s. III d. C. Museo Nacional del Bardo, Túnez. 


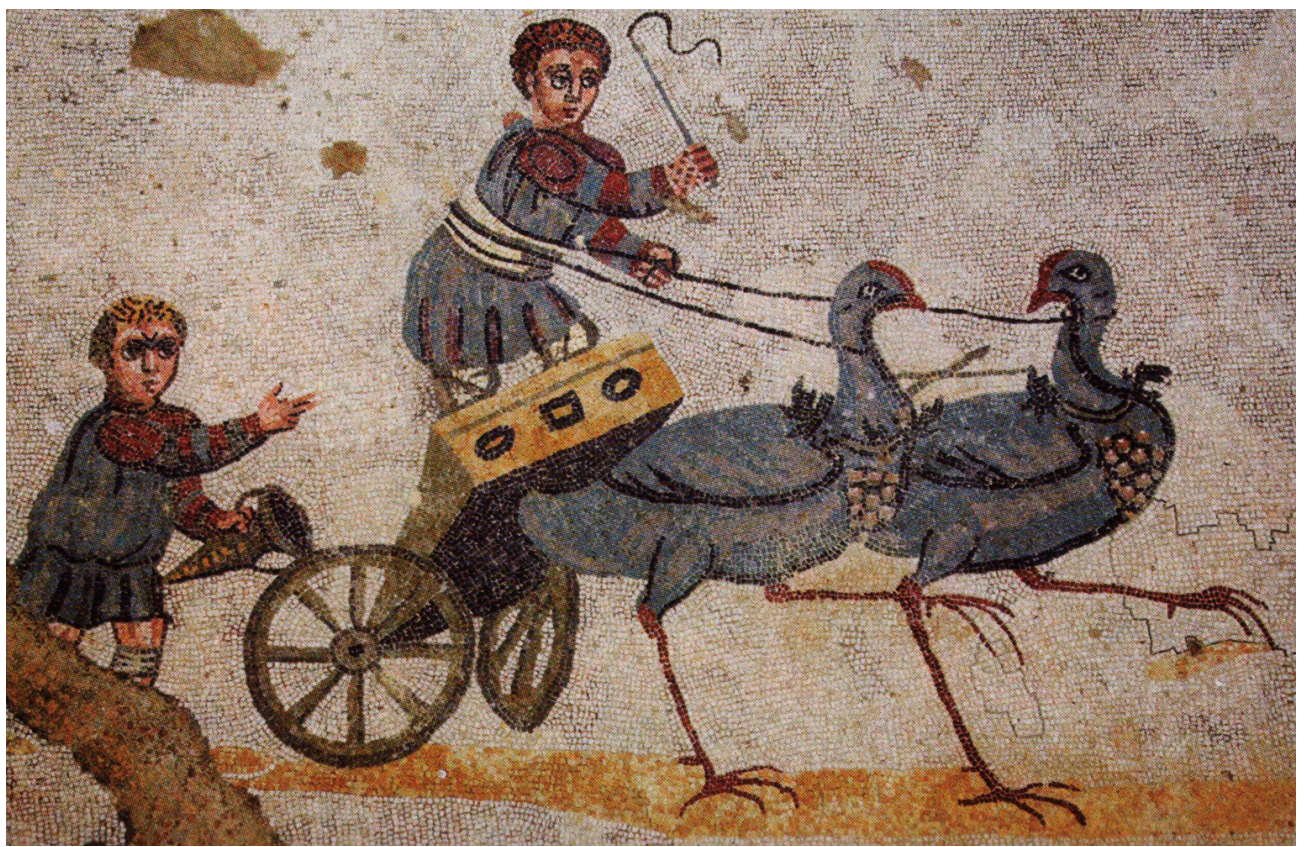

Figura 3. Mosaico de la villa romana del Casale, Piazza Armerina (Sicilia), s. Iv d. C. Fuente: anónimo.

mosaicos mediterráneos muestran aves inmediatamente antes de embarcar y al desembarcar durante su traslado en barco a Roma (uilla romana del Casale, Piazza Armerina, Sicilia, s. IV d. C.) (fig. 1), enfrentándose a un gran felino y a un oso negro (Museo Nacional del Bardo, Túnez, s. III d. C.) (fig. 2) y tirando de un carro en carreras de bigas (uilla romana del Casale, Piazza Armerina, Sicilia, s. IV d. C.) (fig. 3). Un mosaico de la villa de Mértola (Portugal, s. vi d. C.) es el único que incorpora un avestruz en una escena de cetrería (Pimenta y Moreno-García, 2007). En el mosaico de la iglesia bizantina de Petra (s. v d. C.) y en uno de los cuadros de la iglesia de Qasr Libya (mediados s. vi d. C.) aparecen avestruces junto con otros animales. Datos adicionales de carácter iconográfico los aporta la numismática, aunque en una emisión de la ceca de Alejandría de época de Antonino Pío (138139 d. C.) el avestruz ha sido también interpretado como un ave fénix (Shanawany, 1999: 3). Más clara parece la atribución del ave en una moneda de época de Gordiano III (238-244 d. C.), acuñada en Tracia y encontrada en Hadrianópolis (Varbanov, 2002, n. ${ }^{\circ} 3833$ ).

Constancia de avestruces en época medieval la tenemos en el Libro de las Aves de Hugo de Folieto (Rebelo, 1999) (fig. 4), escrito entre 1132 y 1152, y copiado en 1184 en otro libro epónimo encontrado en el monasterio de Lorvão (Coímbra, Portugal) (Mota et al., 1965), El libro de las utilidades de los animales (s. XIV d. C.) (Ruiz, 1990: 167), y en la crónica de Alfonso XI (1340), donde, entre los regalos remitidos por el sultán de Marruecos Abu Hassan al monarca castellano, se mencionan avestruces (Morales-Muñiz, 2000: 266). 


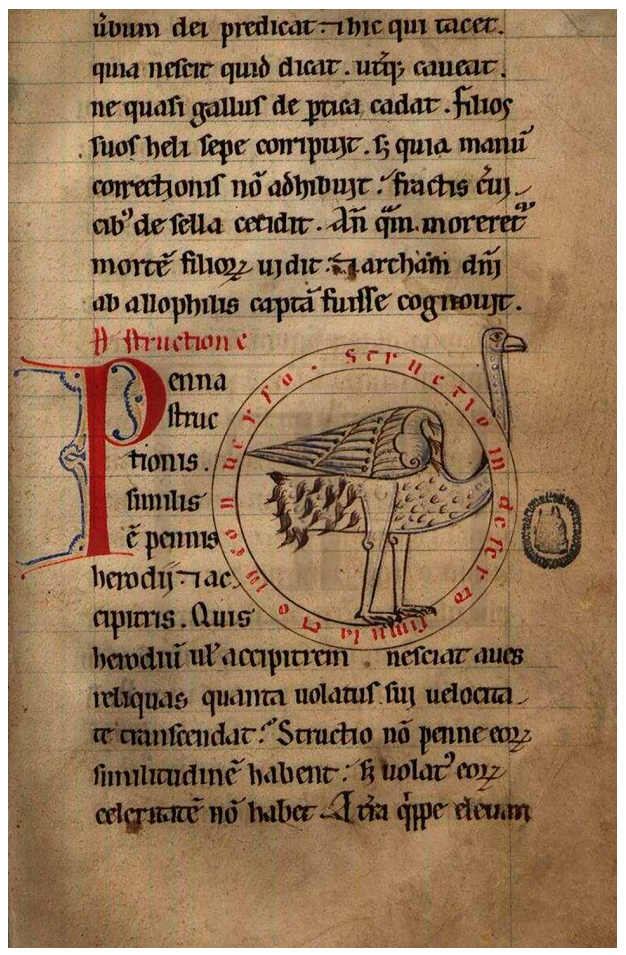

Figura 4. Ilustración del Livro das Aves. Arquivo Nacional Torre do Tombo.

La presencia del avestruz en la literatura e iconografía se constata por tanto desde el siglo v a. C., y ya de forma continuada hasta el siglo XV, cuando el galeno Jerónimo Münzer los cita como mascotas en los castillos de Almería y Fiñana (Puyol, 2010: 78-83). Este último dato da a entender que el animal, y no solo sus productos, transitó por la península ibérica durante un lapso temporal que, en ausencia de registros arqueológicos, no podemos acotar con precisión. Lo que sí consta en esos momentos es el haber formado parte de los primeros zoológicos medievales (menageries), al ser obsequio recurrente entre las cortes medievales (Morales-Muñiz, 2000).

\section{Contexto arqueológico}

El teatro romano constituye el edificio público de ocio y representación del poder más importante de los hasta ahora hallados en Cartagena, la romana Colonia Urbs Iulia Nova Carthago. La ciudad fue fundada por el general cartaginés Asdrúbal con el nombre de QartHadasht ('nueva ciudad') hacia el 228-227 a. C., según relata Polibio (Historias, X.10.1). En 
el año 209 a. C., la ciudad fue conquistada por el general romano Publio Cornelio Escipión en el marco de la Segunda Guerra Púnica (Ramallo, 2019). Hacia finales del siglo ir a. C. se inicia un proceso de renovación urbanística, que se acelera a partir de época augustea. En este contexto, el teatro se erige en la última década del siglo i a. C. y se ocupa de manera ininterrumpida con dicha función hasta el siglo v d. C., cuando sobre sus estructuras, en parte reaprovechadas, se edifica un mercado/almacén. Posteriormente, en el amplio solar inicialmente ocupado por los muros romanos, se levantan y superponen sucesivamente barrios domésticos y construcciones de época bizantina, islámica, bajomedieval, moderna y contemporánea. El ciclo se cierra con la definitiva identificación del edificio de espectáculos, su excavación y musealización, para lo que ha sido necesario desmantelar parte de las estructuras modernas superpuestas (Ramallo, 2007).

El complejo arqueológico se halla emplazado en la ladera noroccidental del cerro de la Concepción, el más elevado y de mayores dimensiones de los cinco que configuran la topografía de la ciudad (fig. 5). Las excavaciones sistemáticas se iniciaron en 1988, desarrollándose de forma ininterrumpida hasta el año 2002, cuando comenzaron los estudios y trabajos de restauración, culminados en julio de 2008. El resto óseo de Struthio camelus que da pie a este trabajo se encontró en la campaña de 1995, en la unidad estratigráfica 4699, que corresponde al relleno de una fosa de 1,20 m de diámetro utilizada como basurero y excavada en el depósito preexistente. Se asocia a la fase 9, en la secuencia cronocultural establecida para el yacimiento, un período poco definido arqueológicamente que se desarrolla entre la destrucción del mercado/almacén, erigido sobre las ruinas del teatro en la segunda mitad del siglo v, y la construcción de un barrio portuario sobre las estructuras anteriores a mediados del siglo VI (Ramallo et al., 2013) (fig. 6). En este sentido, la datación del contexto arqueológico coincide con la obtenida por ${ }^{14} \mathrm{C}$ del resto óseo, lo que corrobora el comercio y transporte de esta especie - siquiera de forma excepcional- entre la segunda mitad del siglo v y la primera mitad del siglo vi. En este sentido, Sinesio de Cirene recuerda que los avestruces se exportaban desde la Cirenaica incluso a comienzos de la quinta centuria, quizás todavía para espectáculos de anfiteatro (Cartas, 134; Toynbee, 1973: 238).

El conjunto de restos faunísticos se encuentra en el relleno de varias fosas que funcionan como vertederos, procurando unos contextos cerrados básicos para la correcta datación, interpretación y determinación de uso de los restos bióticos y abióticos contenidos en ellos. Estos rellenos se escalonan entre la segunda mitad del siglo v y el primer tercio del siglo vII, y se adscriben a diferentes contextos de utilización tales como viviendas o espacios artesanales (Padilla et al., 2019). Nuestro hueso de avestruz se recuperó en el sector 4000, cuadro 4500, concretamente en el relleno de una fosa circular de la primera mitad del siglo vi d. C., según datación establecida por criterios estratigráficos y cerámicos (Ramallo et al., 2002: 295-333). Esta fosa aparecía cubierta por el nivel de destrucción del mercado/ almacén superpuesto al edificio de espectáculos, provocado por un incendio a principios del siglo vi d. C. (Ramallo et al., 2013: 11-22). La fosa-vertedero, de 1,20 metros de diámetro y una potencia de 0,4 metros (UE 4751), se situaba sobre el pavimento enlosado de la exedra del mercado/almacén y está asociada a un contexto de habitación, mal definido 


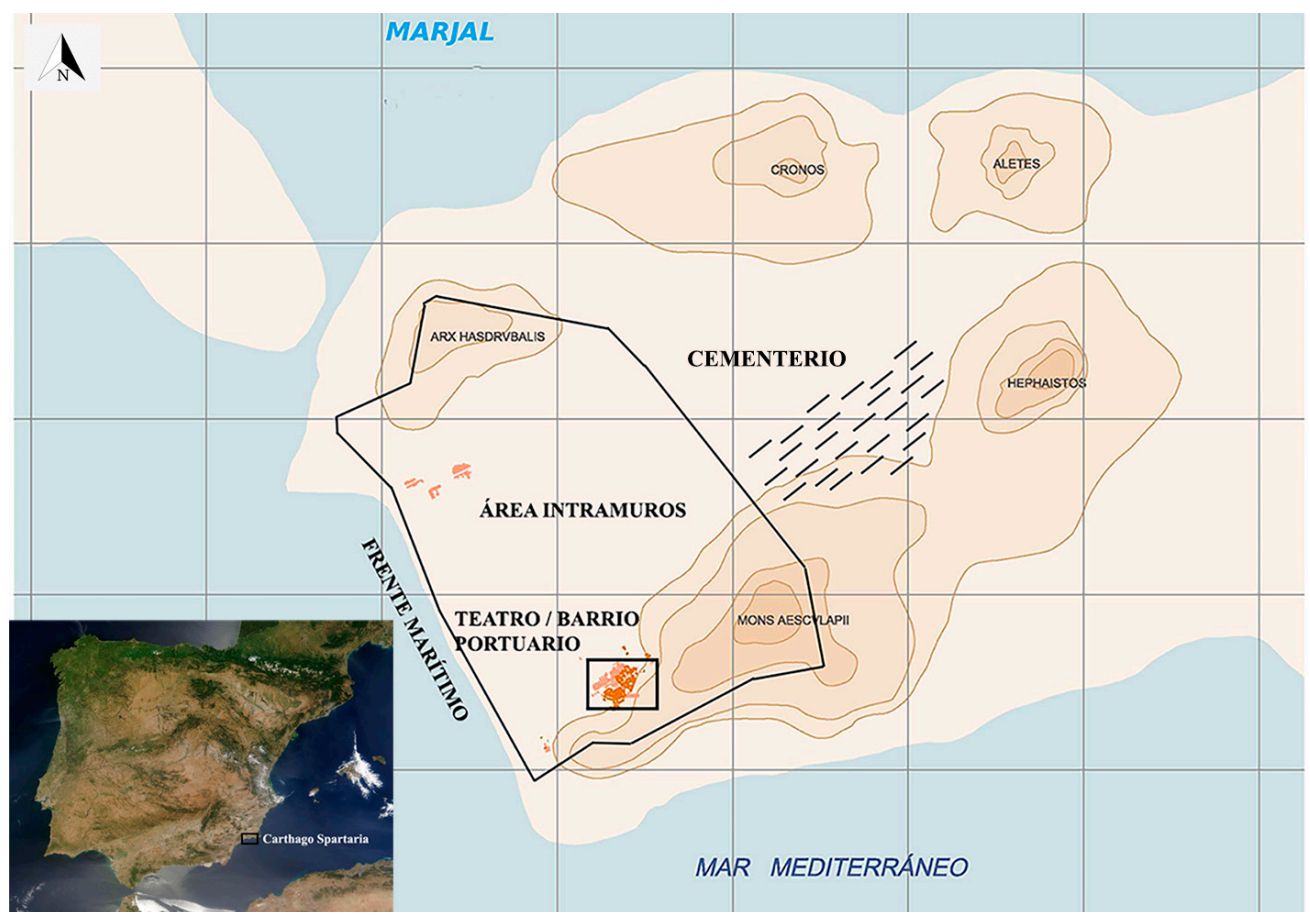

Figura 5. Cartagena con la situación de los cerros y el teatro y el barrio portuario. Archivo: Universidad de Murcia / Museo del Teatro Romano de Cartagena, modificado por los autores.

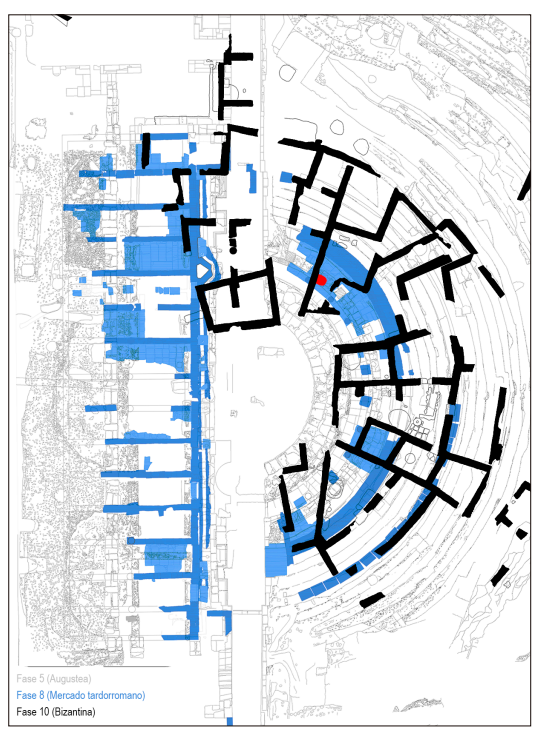

Figura 6. Barrio bizantino sobre la estructura desmantelada del mercado/ almacén. En rojo, el basurero donde se recuperó el fragmento óseo. Archivo: Universidad de Murcia / Museo del Teatro Romano de Cartagena, modificado por los autores. 
desde el punto de vista arqueológico (Ramallo y Ruiz, 1998). Dicho relleno se identifica por un sedimento marrón, muy suelto, con abundancia de pequeñas piedras, carbones y material arqueológico formado por cerámicas toscas tardías de fabricación local, pequeños bronces bajoimperiales ilegibles y restos de fauna caracterizada por la presencia de vacuno, équidos y, en menor medida, porcino, con tan solo un resto constatado de cabra doméstica.

\section{Resultados}

El hueso recuperado es un tarso-metatarso derecho. Conserva la articulación proximal, con una anchura de 78,44 mm, así como el tercio superior de la diáfisis. En norma dorsal (fig. 7.A) se aprecian claramente los dos forámenes nutricios y la erosión acentuada de la cresta medial hipotarsal, estando muy atenuado el desarrollo de la hipotarsal lateral. Este último rasgo resulta mucho más patente en norma proximal (fig. 7.C), donde destaca sobre todo la ausencia de la eminencia intercondilar, rasgo diagnóstico de todas las Ratites. Tal ausencia genera una amplia y cóncava articulación proximal, en la que no puede constatarse el territorio correspondiente al cóndilo lateral y al medial. Por último, en norma plantar (fig. 7.B) destaca el complejo de forámenes nutricios subarticulares y,

Figura 7. Tarso-metatarso del avestruz.

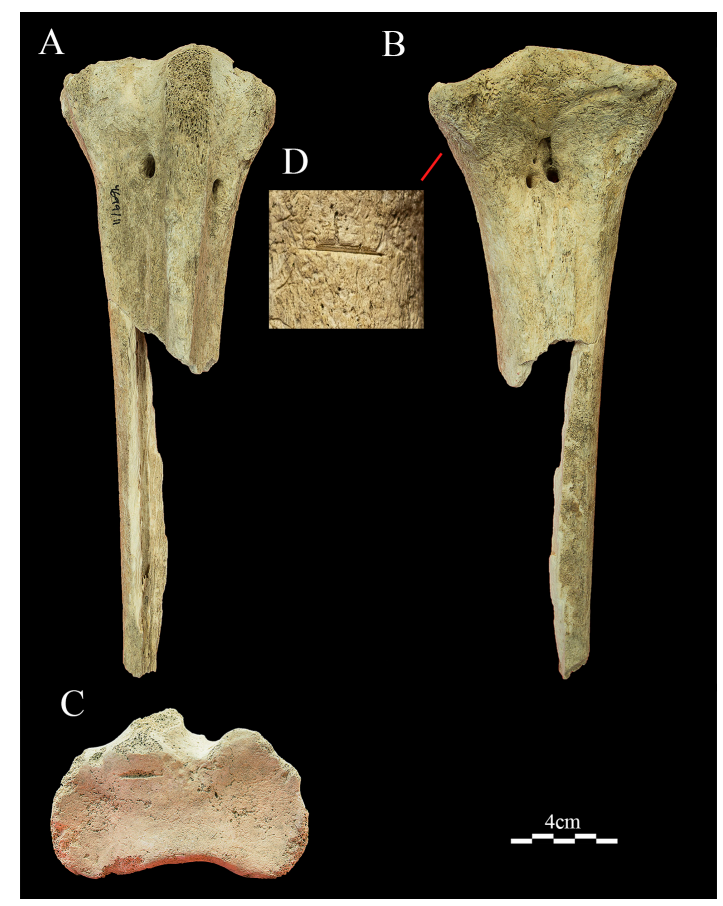


justo por debajo del margen articular, el complejo entramado de canales vasculares. Las erosiones que se aprecian en la capa cortical son tenues y posiblemente originales, resultado de siglos de actividad diagenética dentro de la matriz del depósito, pero la fracturación de la diáfisis, de bordes angulosos, denota la rotura de un hueso que ha perdido gran parte de su fracción orgánica (colágeno), por lo que persiste la duda de si se trata de una fractura antigua (generada antes de la excavación) o reciente, producida en el momento de realizarse la excavación o con posterioridad a esta. También se registró una incisión, que posiblemente fue realizada con un objeto metálico (fig. 7.D), en la cara lateral de la diáfisis. Los valores de la anchura corresponden a los de un individuo subadulto-adulto, lo que dificulta la asignación del sexo, asunto complejo en cualquier caso por no presentar el tarso-metatarso de esta especie, a diferencia de otros huesos y porciones apendiculares, un dimorfismo sexual marcado.

La datación absoluta por ${ }^{14} \mathrm{C}$, realizada en el Beta Analytic Radiocarbon Dating Laboratory mediante AMS, arroja un intervalo de calibración que oscila entre el 398-539 cal. DC (1552-1411 cal. BP) con un nivel de confianza del $95 \%$ a $2 \sigma$ (tabla 1), lo que aproxima una fecha media situada en el $1600+/-30$ BP (468 \pm 30 d. C.), que coincidiría plenamente con el período de actividad del mercado/almacén.

Tabla 1. Datación radiométrica ${ }^{14} \mathrm{C}$ sobre restos óseo

\begin{tabular}{|c|c|c|c|c|c|c|c|}
\hline \multirow[b]{2}{*}{ Fase } & \multirow[b]{2}{*}{$\begin{array}{l}\text { Identificación } \\
\text { de la muetra }\end{array}$} & \multirow[b]{2}{*}{$\begin{array}{l}\text { Identificación } \\
\text { del laboratorio }\end{array}$} & \multirow[b]{2}{*}{ Datación BP } & \multirow[b]{2}{*}{$\begin{array}{l}\text { Datación BP } \\
\text { calibrada }\end{array}$} & \multicolumn{2}{|c|}{ Calibración en años AD } & \multirow[b]{2}{*}{ Mediana } \\
\hline & & & & & $\begin{array}{l}\text { Intervalos } \\
\text { provabilidad a } 1 \sigma\end{array}$ & $\begin{array}{l}\text { Intervalos } \\
\text { provabilidad a } 2 \sigma\end{array}$ & \\
\hline TR-9 & $\begin{array}{l}\text { CP-4699-920-1 } \\
\text { (Hueso, no } \\
\text { quemado) }\end{array}$ & Beta-540157 & $1600+/-30 \mathrm{BP}$ & 1552-1411 cal. BP & $\begin{array}{l}(38,1 \%) \\
486-534 \text { cal. AC } \\
(18,3 \%) \\
410-434 \text { cal. AC } \\
(11,8 \%) \\
451-470 \text { cal. AC }\end{array}$ & $\begin{array}{l}(95,4 \%) \\
398-539 \text { cal. AC }\end{array}$ & $468 \mathrm{AC}$ \\
\hline
\end{tabular}

*Calibration: BetaCal3.21: HPD method: INTCAL 13. References to Probability Method: Bronk Ramsey, C., 2009, Bayesian analysis of radiocarbon dates, Radiocarbon 51/1, 337-360. References to Database INTCAL 13: Reimer, et al., 2013, Radiocarbon 55/4.

\section{Discusión y conclusiones}

Son contados los restos de avestruz que documenta el registro arqueológico. Aparte del aquí referido, solo se tiene constancia documentada de un esternón, una tibia y un fragmento de fémur en el Anfiteatro Flavio de Roma (Luzj, 1894: 3-7, extraído de De Grossi Mazzorin et al., 2005), así como de otro tarso-metatarso en la Meta Sudans, fuente monumental situada entre el Arco de Constantino y el Coliseo (De Grossi Mazzorin, 1995: 309318). En otras palabras, cinco restos para un período de más de veinte siglos. Este hecho 
no deja de resultar llamativo, toda vez que hablamos de un ave repetidamente referenciada en las fuentes literarias e iconográficas. Habida cuenta del tamaño de sus huesos y lo diagnóstico de su morfología, no parece lógico achacar esta ausencia a un conocimiento osteológico deficiente (sin duda real) o a una recogida deficiente del material óseo en las excavaciones. Aunque puedan existir otras razones que ahora se nos escapan, habremos de aceptar como más parsimoniosa la hipótesis de que, en efecto, esta escasez de registros refleja una muy casual presencia del ave en el ámbito continental europeo.

En este contexto, el hallazgo de Cartagena constituye un hecho excepcional. La presencia del avestruz en un yacimiento de gran importancia cronocultural, como es el teatro romano de Cartagena, y su asociación con el momento de actividad del mercado/almacén pueden ayudarnos a definir usos y justificar su presencia en el registro arqueológico.

¿Cómo y con qué fin llegó este animal al depósito arqueológico? Consideramos que solo puede haber dos respuestas plausibles, siendo la primera el comercio marítimo con el norte de África, comercio que se hace patente por el gran número de ánforas de los talleres de la costa de Cartagena que se han documentado en Nador, especialmente de época tardía (Quevedo, 2019). En sentido inverso, y apoyando este último dato, cabe señalar la gran cantidad de envases anfóricos y vajilla de mesa del norte de África, especialmente del área tunecina, en las unidades estratigráficas de esta época, frecuencia que se puede hacer extensiva a otros enclaves contemporáneos del tramo litoral que flanquea la ciudad (Ramallo, 2000). La otra posibilidad, a nuestro juicio menos probable, es que existiera un criadero de avestruces en la zona, aunque no hay testimonios de la existencia de granjas para su cría en cautividad hasta el siglo XIX. Lo cierto es que no existen pruebas de que, en época romana, fuera de las aves norteafricanas, existieran poblaciones de avestruces establecidas en las tierras de la margen norte del Mediterráneo; probablemente, de ser así, sin duda su frecuencia en el registro arqueológico hubiera sido muy superior a la hasta ahora constatada.

El segundo interrogante de interés sería el referido a la utilidad del ave. Antes hemos apuntado los diferentes usos que tuvo el avestruz a lo largo de la historia: como animal de compañía, en los juegos o venationes y como alimento, uso que podría haberse conjuntado con los anteriores. Al disponer de un solo elemento óseo parece improbable la opción de que fuera un animal de compañía, ya que, como nos consta que ocurre con tantas mascotas, es frecuente encontrar más elementos de un mismo ejemplar en un depósito, con frecuencia en conexión anatómica, y no suele ser común encontrarlos en vertederos sino en contextos mucho más singulares (Prummel, 1997; Morales-Muñiz, 2000). La cronología del depósito, la procurada por el propio resto óseo, así como su carácter y ubicación, podrían descartar su utilización en juegos circenses o de anfiteatro, al menos en los edificios, ya arruinados, establecidos para tal fin (Pérez et al., 2014). Por otra parte, encontrar un tarso-metatarso, elemento desprovisto de carne que en las aves se suele descartar durante el proceso de descuartizamiento, refuerza la idea de una actividad comensal o alimentaria. Tal hipótesis encaja con la incisión constatada en la diáfisis (fig. 7.D). El aprovechamiento cárnico no invalida usos previos relacionados aquí con espectáculos en el viejo teatro, edificio que en la segunda mitad del siglo IV y hasta inicios del siglo v, al menos, debió 
tener un carácter polivalente, tras el abandono del anfiteatro y la reestructuración del sector de la escena. Posteriormente, el ave podría haber sido aprovechada en algún acto de comensalidad, tal y como apunta la incisión. En cualquier caso, la cronología absoluta del hueso, dentro de la segunda mitad del siglo v, introduce cierto grado de incertidumbre en esta lectura, ya que, según la interpretación arqueológica, en aquel momento el teatro habría perdido ya cualquier función relacionada con los espectáculos.

Si aceptáramos la hipótesis del consumo, resulta patente que estaríamos, en todo caso, ante una comensalidad fuera de lo común. Si, como parece más plausible, el animal implica comercio marítimo, a falta de mejor información, sabemos que ello comportaría riesgos. Así, en una expedición marítima desde Egipto o Etiopía a Hamburgo realizada en 1869, de los cuatro avestruces embarcados ninguno sobrevivió (Openshaw, 1993). Bien es cierto que, en el caso de Cartagena, además de una climatología más benigna para el ave, la duración del trayecto entre ambas orillas del Mediterráneo alcanzaría un máximo de 72 horas (Arnaud, 2005: 159-160), que podrían quedar reducidas a 48 horas, caso de que el trayecto fuera desde Carthago Nova a Iol Caesarea (Cherchel), población con la que las relaciones comerciales debieron ser muy estrechas desde inicios de época imperial (Cerezo Andreo, 2016: 707). En cualquier caso, inferimos que el transporte de este tipo de animales suponía una apreciable inversión económica, lo que limitaba su consumo a grupos muy selectos de la población. En Roma, su presencia aparece invariablemente asociada a espectáculos impulsados por los emperadores y a la de otros animales de carácter exótico, y con frecuencia también a banquetes imperiales. En este ámbito, y en un entorno mucho más provincial, cabe preguntarse qué grupos sociales pudieron ser los consumidores de tal vianda. Por ahora, sin apenas evidencias en los registros arqueológicos, solo podemos apuntar esta teoría como la más plausible.

Para concluir, cabe señalar que es mucho el camino que queda por recorrer para responder a las preguntas planteadas. Poder completar el registro arqueológico del avestruz complementará los datos que nos ofrecen las fuentes literarias e iconográficas, y dará respuesta a la cuestión de si esta especie tuvo en algún momento o circunstancia una presencia importante en suelo europeo, como sería la derivada de la cría de ejemplares en granjas, o tan solo una presencia puntual, derivada de un comercio también puntual, como de momento parece apuntarnos la arqueología.

\section{Agradecimientos}

Este trabajo se ha realizado en el marco del proyecto de investigación Carthago Nova desde su entorno litoral. Paleotopografía y evolución medioambiental del sector central del sureste ibérico. Dinámica poblacional y productiva (HAR2017-85726-C2-1-P), del Ministerio de Ciencia e Innovación, Agencia Estatal de Investigación,10.13039/501100011033/, parcialmente financiado con fondos FEDER: Una manera de hacer Europa. 


\section{Bibliografía}

ARNAUD, P., 2005, Les routes de la navigation antique. Itinéraires en Méditerranée, Editions Errance, París.

BLÁZQUEZ, J. M., 1974, Circo y fieras en la Roma antigua. Pantomimas y naumaquias, Jano 119, 91-97.

BRYSBAERT, A., 2013, «The chicken or the egg?» Interregional contacts viewed through a technological lens at Late Bronze Age Tiryns, Greece, Oxford Journal of Archaeology 32/3, 233-256.

CALVO, C., 1990, Opiano: De la caza. De la pesca, Biblioteca Clásica Gredos 134, Gredos, Madrid.

CAMPS-FABRER, H., 1995, L'homme et l'autruche à travers le temps, en R. CHENORKIAN (ed.), L'homme méditerranéen. Mélanges offerts à Gabriel Camps, professeur émérite de l'Université de Provence, Publications de l'Université de Provence, Aix-en-Provence, 427-452.

CANTÓ, J., 2002, Plinio el Viejo: Historia natural, Letras Universales, Cátedra, Madrid.

CEREZO ANDREO, F., 2016, Los puertos antiguos de Cartagena. Geoarqueología, Arqueología Portuaria y Paisaje Marítimo. Un estudio desde la Arqueología Náutica [en línea], Tesis doctoral, Universidad de Murcia, Murcia. Disponible en $<$ https://digitum. um.es/digitum/handle $/ 10201 / 58 /$ browse?type= author\&order $=$ ASC\&rpp $=20$ \&value $=$ Cerezo + Andr eo $\% 2 \mathrm{C}+$ Felipe $>$.

CRAMP, S., 1975, Handbook of the Birds of Europe, the Middle East and North Africa. Vol. 1: Ostrich to Ducks, Oxford University Press, Oxford.

CROMPTON, W. M., 1918, A Carved Slate Palette in the Manchester Museum, The Journal of Egyptian Archaeology 5/1, 57-60.

DE GROSSI MAZZORIN, J., 1995, La fauna rinvenuta nell'area della Meta Sudans nel quadro evolutivo degli animali domestici in Italia, en R. PERETTO (ed.), Atti del I Convegno Nazionale di Archeozoologia (Rovigo, 5-7 marzo 1993), Padusa Quaderni 1, 309-318.
DE GROSSI MAZZORIN, J., MINNITI, C. y REA, R., 2005, De ossibus in anphitheatro Flavio effossis: 110 anni dopo i rinvenimenti di Francesco Luzj, en G. MALERBA y P. VISENTINI (eds.), Atti del $4^{\circ}$ Convegno Nazionale di Archeozoologia (Pordenone, 13-15 novembre 2003), Quaderni del Museo Archeologico del Friuli Occidentale 6, 337-348.

GIBBON, E., 1910, The History of the Decline and Fall of the Roman Empire. Volume I, Fred de Fau $\delta$ Company, Nueva York.

LUZJ, F., 1894, De ossibus in Anphytheatro Flavio effossis, Ephemeride Zoologicae Res 1/1, 3-7.

MARTíN, J. A., 2018, Abastecimiento, transformación y comercialización de las cáscaras de huevo de avestruz en la Península Ibérica e islas Baleares durante el I milenio a. C., Antiquitas 30, 23-31.

MORALES-MUÑIZ, D. C., 2000, La fauna exótica en la Península Ibérica: apuntes para el estudio del coleccionismo animal en el Medievo hispánico, Espacio, Tiempo y Forma, Serie III, H. ${ }^{a}$ Medieval 13 233-270.

MOTA, J., MATTOS, R., LÚCIA, V. y ROSSI, N., 1965, Livro das Aves, Instituto Nacional do Livro / MEC, Río de Janeiro.

OPENSHAW, P., 1993, Transportation of wild herbivores, en A. MCKENZIE (ed.), The capture and care manual: capture, care, accommodation and transportation of wild African animals, Wildlife Decision Support Services, Sudáfrica, 194-199.

PADILLA, J. E., MORALES, A. y RAMALLO, S. F., 2019, Recursos y hábitos de consumo de la cabaña ganadera en Carthago Spartaria en época bizantina, Zephyrus LXXXIII/1, 165-183.

PAJUELO, A., 2016, Los restos de animales de Montelirio, en A. FERNÁNDEZ, L. GARCÍA y M. DÍAZ-ZORITA (eds.), Montelirio. Un gran monumento megalítico de la Edad del Cobre, Junta de Andalucía, Consejería de Cultura, Sevilla, 455-467.

PASTOR, B. (ed.), 1987, Marco Gavio Apicio: Cocina romana, Editorial Coloquio, Madrid. 
PELLICER, M., 1995, Las culturas del neolíticocalcolítico en Andalucía Oriental, Espacio, Tiempo y Forma, Serie I, Prehistoria y Arqueología 8, 81-134.

PÉREZ, J., BERROCAL, M. C. Y FERNÁNDEZ, F., 2014, El ocaso de los edificios de Spectacula en Hispania: el anfiteatro romano de Carthago Nova, en S. F. RAMALLO y A. QUEVEDO (eds.), Las ciudades de la Tarraconense oriental entre los S. II-IV d. C.: evolución urbanística y contextos materiales, Editum, Murcia, 321-339.

PICÓN, V. y CASCÓN, A. (eds.), 1989, Historia Augusta, Clásica, Akal, Madrid.

PIMENTA, C. y MORENO-GARCÍA, M., 2007, A Arqueologia e as avestruzes na Península Ibérica, Pardela 29, 24-25.

PRUMMEL, W., 1997, Evidence for hawking (falconry) from bird and mammal bones, International Journal of Osteoarchaeology 7, 333-338.

PUYOL, J., 2010, Jerónimo Münzer. Viaje por España y Portugal en los años 1494 y 1495, Biblioteca Virtual Miguel de Cervantes, Alicante, 78-83.

QUEVEDO, A., 2019, Dinámicas comerciales entre Hispania y Mauretania Caesariensis. Algunas reflexiones a partir de la evidencia cerámica (ss. I-v d. C.), Zephyrus 83, 59-77.

RAMALLO, S. F., 2000, Carthago Spartaria, un núcleo bizantino en Hispania, en G. RIPOLL y J. M. GURT ESPARRAGUERA (eds.), Sedes regiae (ann. 400-800), Reial Acadèmia de Bones Lletres, Barcelona, 579-611.

RAMALLO, S. F., 2007, Una experiencia en la recuperación del patrimonio arqueológico: el teatro de Carthago Nova, Mainake 29, 139-164.

RAMALLO, S. F., 2019, Problemas en torno a la conquista de Qart Hadasth por Escipión. Nuevos datos desde la geoarqueología, en B. VALLORI, C. RUEDA y J. P. BELLÓN (eds.), Accampamenti, guarnigioni e assedi durante la Seconda Guerra Punica e la conquista romana (secoli III-I a. C.): prospettive archeologiche, Quasar, Roma, 9-28.

RAMALLO, S. F. y RUIZ, E., 1998, El teatro romano de Cartagena, KR Editorial, Murcia.
RAMALLO, S. F., RUIZ, E., MURCIA, A. J. y GUILLERMO, M., 2013, La secuencia históricoarqueológica del Cerro de la Concepción a través del material cerámico, Anales de Prehistoria y Arqueología 29, 11-22.

RAMALLO, S. F., SAN MARTÍN, P. A. y RUIZ, E., 2002, Excavaciones arqueológicas en el teatro romano de Cartagena. Campaña de 1995 , Memorias de Arqueología 10, 295-333.

REBELO, M. I., 1999, Livro das Aves, Edições Colibri, Lisboa.

REESE, D. S., 1985, Appendix III. Shells, ostrich eggshells and other exotic faunal remains from Kition, en V. KARAGEORGHIS y M. DEMAS (eds.), Excavations at Kition. V: The Pre-Phoenician Levels, Part II, Department of Antiquities of Cyprus, Nicosia, 371-382.

RICHTER, W., 1975, Der kleine Pauly, Vol. 5, Col. 396, s. v. Strauss.

RUIZ, C., 1990, Ibn al-Durayhim al-Mawsili: Libro de la utilidad de los animales, Editorial Patrimonio Nacional, Madrid.

SHANAWANY, M. M., 1999, Ostrich production systems. Part I: A review, FAO Animal Production and Health, Paper 144, Roma.

TORRES, J., 1990, Herodiano: Historia del Imperio romano después de Marco Aurelio, Traducción, introducción y notas, Biblioteca Clásica Gredos 80, Gredos, Madrid.

TOYNBEE, J. M. C., 1973, Animals in Roman Life and Art, Pen and Sword Archaeology, Yorkshire.

VARA, J., 1989, Claudio Eliano: Historia de los animales, Clásica, Akal, Madrid.

VARBANOV, I., 2002, Greek Imperial Coins and Their Values. The Local Coinages of the Roman Empire. Vol. III: Thrace, Adicom Publications, Burgas.

VUKOVIĆ, S. I., 2015, Životinje u rimskim amfiteatrima. Studija slučaja amfiteatra $u$ Viminacijumu (Animals in Roman amphitheatres. Viminacium amphiteatre case study) [en línea], Tesis doctoral, Belgrado. Disponible en <http:// nardus.mpn.gov.rs/bitstream/id/27014/ Disertacija453.pdf $>$. 